J. Dairy Sci. 95:6571-6581

http://dx.doi.org/10.3168/jds.2011-5170

(C) American Dairy Science Association ${ }^{\circledR}, 2012$.

\title{
The effects of social contact and milk allowance on responses to handling, play, and social behavior in young dairy calves ${ }^{1}$
}

\author{
L. R. Duve,$^{\star 2}$ D. M. Weary, $\dagger$ U. Halekoh, ${ }^{\star}$ and M. B. Jensen ${ }^{\star}$ \\ *Department of Animal Science, Aarhus University, 8830 Tjele, Denmark \\ †Animal Welfare Program, University of British Columbia, Vancouver, British Columbia V6T 1Z4, Canada
}

\begin{abstract}
The aim of this study was to investigate the effects of social contact and milk allowance on social behavior, play behavior, and responses to handling in dairy calves. Forty test calves and 16 companion calves were allocated to 1 of 5 treatments from birth to 4 wk of age: (1) housed singly and fed $5 \mathrm{~L}$ of milk/d; (2) housed singly and fed $9 \mathrm{~L}$ of milk/d; (3) housed in pairs and fed $5 \mathrm{~L}$ of milk/d; (4) housed in pairs and fed $9 \mathrm{~L}$ of milk/d; or (5) kept with the dam and fed $9 \mathrm{~L}$ of milk/d. From 4 to 6 wk of age, all calves were offered $5 \mathrm{~L}$ of milk/d to promote intake of solid feed before weaning. At 6 wk of age, all calves were weaned, and at 7 wk of age, they were grouped ( 7 calves/group: 1 test calf from each treatment and 2 companion calves). The response to restraint during blood sampling was recorded weekly; singly housed calves struggled more during restraint than did calves kept with the dam, and pair-housed calves struggled at an intermediate level. Play behavior was recorded for $20 \mathrm{~min} / \mathrm{wk}$ after the provision of fresh straw; calves housed singly and fed a low milk allowance spent less time playing than did calves in all other treatments. Three days after grouping, calves were subjected to a feed competition test; calves receiving the high milk allowance and housed in pairs spent more time feeding than did those receiving the high milk allowance and housed singly, with all other treatments showing intermediate responses. These results indicate that social contact decreased responses to restraint and increased play and competitive success. The high milk allowance increased play but reduced competitive success after grouping. Lower responses to restraint indicated less responsiveness to stress. Play is considered an indicator of positive wel-
\end{abstract}

\footnotetext{
Received November 22, 2011.

Accepted July 5, 2012.

${ }^{1}$ An earlier draft of this paper was included in Linda Rosager Duve's $\mathrm{PhD}$ thesis titled "The effect of pair housing on social behavior, social relationships and welfare of dairy calves" (Faculty of Science and Technology, Aarhus University, 2012).

${ }^{2}$ Corresponding author: Linda.duve@agrsci.dk
}

fare, and competitive success helps calves succeed in a group environment.

Key words: welfare, dairy calf, social contact, milk allowance

\section{INTRODUCTION}

Separation of the cow and calf within $24 \mathrm{~h}$ of birth is a common practice in dairy farming. After separation from the dam, the calf is usually housed in an individual pen, and to encourage early intake of concentrates, the supply of milk is often limited to 4 to $6 \mathrm{~L} / \mathrm{d}$. In contrast, Holstein calves suckling the dam consume between 8 and $14 \mathrm{~kg} / \mathrm{d}$ (7.8 to $13.6 \mathrm{~L} / \mathrm{d}$; de Passillé and Rushen, 2006).

Welfare concerns have been raised about individual housing of preweaned calves (e.g., Raussi et al., 2003; De Paula Vieira et al., 2010), in part because this contrasts with the more natural situation in which calves are reared by the dam in groups consisting of cows and calves (Bouissou et al., 2001; Krohn, 2001). Under these more natural conditions, calves receive maternal care, including grooming and nursing (von Keyserlingk and Weary, 2007), and interact with peers from approximately 1 wk of age (Wood-Gush et al., 1984; Vitale et al., 1986). Calves are willing to work harder for full social contact with a peer than for limited social contact (i.e., they are more motivated to have full social contact; Holm et al., 2002). The presence of another calf, especially a familiar calf, has a calming effect on the behavioral response in various situations that are considered stressful (Grignard et al., 2000; Takeda et al., 2003; Færevik et al., 2006). Group-housed calves also reacted less fearfully when exposed to an unfamiliar calf or when placed in a novel arena compared with individually housed calves (Jensen et al., 1997), and group housing facilitates the development of normal social behavior (Veissier et al., 1994; Jensen et al., 1999).

Welfare concerns have also been raised about low milk allowances. When offered whole milk ad libitum, Holstein calves consume 10 to $12 \mathrm{~L} / \mathrm{d}$, and calves offered the conventional 4 to $6 \mathrm{~L} / \mathrm{d}$ are unable to meet their nutrient requirements for optimal growth during 
the first month of life (Jasper and Weary, 2002; Khan et al., 2007; Sweeney et al., 2010). A high milk allowance may also increase the duration of play behavior in dairy calves (Krachun et al., 2010); this finding supports the idea that young mammals perform more play behavior when their nutritional needs are met (for a review, see Held and Špinka, 2011). Furthermore, the performance of play behavior may be associated with positive emotions (Špinka et al., 2001; Boissy et al., 2007), and play behavior is suggested to be an indicator of positive welfare (Yeates and Main, 2008; Held and Špinka, 2011).

Social contact with peers and a high milk allowance may mitigate the effects of early separation from the dam. However, the combined effects of social contact with a peer and a high milk allowance have, to our knowledge, never been tested or compared with maternal contact. The aim of this study was therefore to investigate the effect of social contact with a peer and the effect of a high milk allowance on parameters related to calf welfare (including reaction to handling, play behavior, and competitive skills), and to compare this with the effect of both the standard housing conditions (single housing and a low milk allowance) and staying with the dam, respectively.

\section{MATERIALS AND METHODS}

The study took place at the cattle research facilities at Research Centre Foulum, Aarhus University, Denmark. Animals were cared for and treated according to a protocol approved by the Danish Animal Experiments Inspectorate, The Danish Ministry of Justice, Copenhagen, Denmark.

\section{Animals and Treatments}

Fifty-six Holstein-Friesian calves (8 blocks of 7 calves) born from mid-September to mid-December 2010 were included in the study. Within block, calves were allocated to 5 different treatments at random. The treatments were as follows: SL-single housing on a low milk allowance (5 L of milk/d), SH - single housing on a high milk allowance (9 L of milk/d), PL-pair housing on a low milk allowance $(5 \mathrm{~L}$ of milk/d; 1 test calf, 1 companion calf), $\mathbf{P H}$ - pair housing on a high milk allowance $(9 \mathrm{~L}$ of milk/d; 1 test calf, 1 companion calf), and $\mathbf{C H}$ - calf housed with the dam on a high milk allowance $(9 \mathrm{~L}$ of milk/d). The test calf in treatments PL and PH was the younger of the 2 calves in a pair. The age difference within a pair was $\leq 2.5 \mathrm{~d}$. The sex ratios (bull:heifer) of the test calves were 4:4, 6:2, $5: 3,4: 4$, and $6: 2$ for treatments SL, SH, PL, PH, and
$\mathrm{CH}$, respectively. The mean birth weight of the calves was $43 \pm 4.8 \mathrm{~kg}$ (mean $\pm \mathrm{SD}$ ).

To reduce disturbances in the barn, all tests and management procedures (except colostrum feeding) were performed according to the age of the youngest calf in the block. The mean age difference of the calves within a block was $4.9 \pm 2.0 \mathrm{~d}$.

\section{Housing}

All calves were born in individual calving pens in a calving facility less than $100 \mathrm{~m}$ from the calf barn, and all cows were fitted with an udder net before calving to prevent the calves from suckling their dams. The cows in treatment $\mathrm{CH}$ wore the udder net throughout the study. Except for treatment $\mathrm{CH}$, the calves were removed from the dam as soon as possible after birth and temporarily placed in an individual pen without contact with their dam or any other calf. All test calves were moved to the calf barn within 6 to $8 \mathrm{~h}$ of birth, whereas companion calves (treatments PL and $\mathrm{PH}$ ) were kept in an individual pen until the test calf was born. All calves were moved to the calf barn in a cart; the calves on treatment PL and PH were moved together with their social companion; $\mathrm{CH}$ calves were moved with their dam walking beside the cart.

From d 1 to 49, the calves were housed according to treatment in the calf barn. On d 49, all 7 calves in a block were moved together to a group pen in another barn, where they stayed for 1 wk.

Calf Barn. The straw-bedded pens in the calf barn had sides made of vertical metal bars (bar diameter: $2.5 \mathrm{~cm}$; distance between bars: $10 \mathrm{~cm}$ ). The pens for treatment $\mathrm{CH}$ were $4.5 \times 4.5 \mathrm{~m}$. Pens for all other treatments were $3.0 \times 4.5 \mathrm{~m}$ (Figure 1). Adjacent pens in a block were positioned $1.5 \mathrm{~m}$ apart, ensuring that the calves from all treatments were physically, but not visually and acoustically, isolated from the other calves in the barn. The position of each treatment within the row of pens for each block was randomized. All calves were fed $4 \mathrm{~L}$ of colostrum (from their dam) from a teat bottle within $6 \mathrm{~h}$ of birth. Over the next $3 \mathrm{~d}$, they were fed $3 \mathrm{~L}$ of fresh colostrum (from the most recent milking of cows that were within their first 3 milkings after calving) twice a day (0700 and $1500 \mathrm{~h})$ from a teat bucket, and from d 4, colostrum was replaced with whole milk (fresh milk from cows that had not recently calved). Calves on treatments SL and PL received $2.5 \mathrm{~L}$ of milk per feeding (i.e., $5 \mathrm{~L} / \mathrm{d}$ ), and calves on treatments $\mathrm{SH}, \mathrm{PH}$, and $\mathrm{CH}$ received $4.5 \mathrm{~L}$ of milk per feeding (i.e., 9 L/d) until d 28. From d 28, all calves received $2.5 \mathrm{~L}$ of milk per feeding. Milk intakes were reduced for treatments $\mathrm{SH}, \mathrm{PH}$, and $\mathrm{CH}$ to promote 


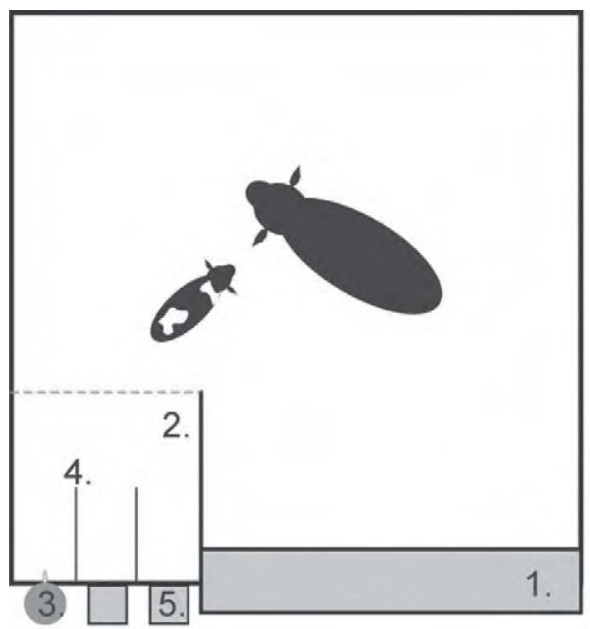

a)
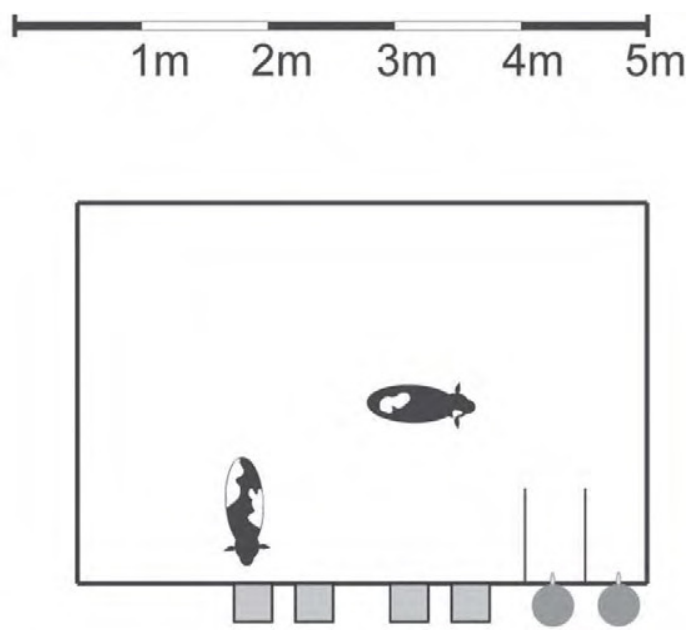

b)

Figure 1. Sketch of the pens used for a) a calf housed with the dam (CH treatment) and b) all other treatments (singly or pair-housed calves). 1) A 3-m-long feed trough and an overhanging hay compartment. 2) Feeding space for the calf, inaccessible to the cow because of a 1.5-m-long partition, positioned at a right angle to the front of the pen, and a 1.5-m-long chain from the end of the partition to the side of the pen. 3) Teat bucket. 4) Milk feeding barriers to reduce competition over milk. All pens were fitted with two 60-cm-high barriers fitted $45 \mathrm{~cm}$ above floor level, which protruded $75 \mathrm{~cm}$ into the pen. The barriers were separated by 32 to $35 \mathrm{~cm}$ (adjusted according to calf size) and positioned the same distance from the corner of the pen. No competition was possible in the pens of calves housed singly and fed $5 \mathrm{~L}$ of milk/d (SL treatment), calves housed singly and fed $9 \mathrm{~L}$ of milk/d (SH), and calves kept with the dam and fed $9 \mathrm{~L}$ of milk/d (CH treatment), but the barriers were nevertheless positioned in these pens to ensure equal space in the home environment for all calves. 5) Troughs for concentrate and hay.

intake of concentrate preweaning (Khan et al., 2007). On d 42 , all calves were weaned.

Calves had free access to water, concentrate, and hay throughout the study. Fresh straw bedding was supplied from Wednesday through Sunday at $0930 \mathrm{~h}$, except in wk 1, when it was supplied daily. The cows in treatment $\mathrm{CH}$ were milked twice a day (0500 and 1400 h) in the home pen.

Artificial lights were on in the barn from 0600 to $2200 \mathrm{~h}$ and dimmed throughout the night. The temperature and humidity fluctuated according to overall weather conditions $\left(9.2 \pm 4.6^{\circ} \mathrm{C}\right.$ and $74.8 \pm 7.0 \%$ relative humidity).

Group Pens. The group pens were straw bedded with solid sides made of plywood. Pens measured $4.0 \times$ $4.8 \mathrm{~m}$, with 1.8-m-high sides. The calves had free access to concentrate from 4 troughs positioned adjacent to each other along the front panel, which allowed all 7 calves to feed at the same time. Concentrate, hay, and water were provided ad libitum.

\section{Handling}

All calves were weighed on Wednesdays when they were 2, 4, and 6 wk old. Blood samples were taken for use in a separate study on Thursdays from wk 1 to 6 . These interventions provided an opportunity to assess the responses to humans and to human handling.
Calves were tested according to the position of their pen in the block, and the order of testing the blocks was rotated. Before testing, the observer entered the pen, walked along all 4 sides of the pen, and made sure that all calves were standing.

Response to Human. This test was conducted in the same way before both the blood sampling and the weighing of the calves. Two handlers and an observer participated. Each individual had specific tasks during the test, and with few exceptions, the same 3 persons were involved in the test each time. For treatments SL and $\mathrm{SH}$, the test began with 1 handler entering the pen, and for treatments PL, PH, and $\mathrm{CH}, 2$ handlers entered the pen ( 1 handler for the test calf and 1 focusing on the social companion). The handler(s) stood motionless along the side of the pen with their arms by their sides for $90 \mathrm{~s}$, with each facing his or her respective calf or cow. During this period, the observer, who was positioned outside the pen, recorded when the calf was in contact with the handler, the latency to contact, and when the calf was $>3 \mathrm{~m}$ away from the handler (equivalent to the corner furthest away from the handler; see definitions of behaviors in Table 1). If the calf voluntarily initiated contact, it was gently brushed along the back with a soft brush (in relation to blood sampling only) and allowed to suck on the fingers of the handler. In relation to contact, the behaviors butting the handler, sucking clothes, and sucking fingers were 
Table 1. Ethogram used during the 2 tests on social behavior (S), during the play behavior test (P), and in relation to blood sampling (B) and weighing $(\mathrm{W})$

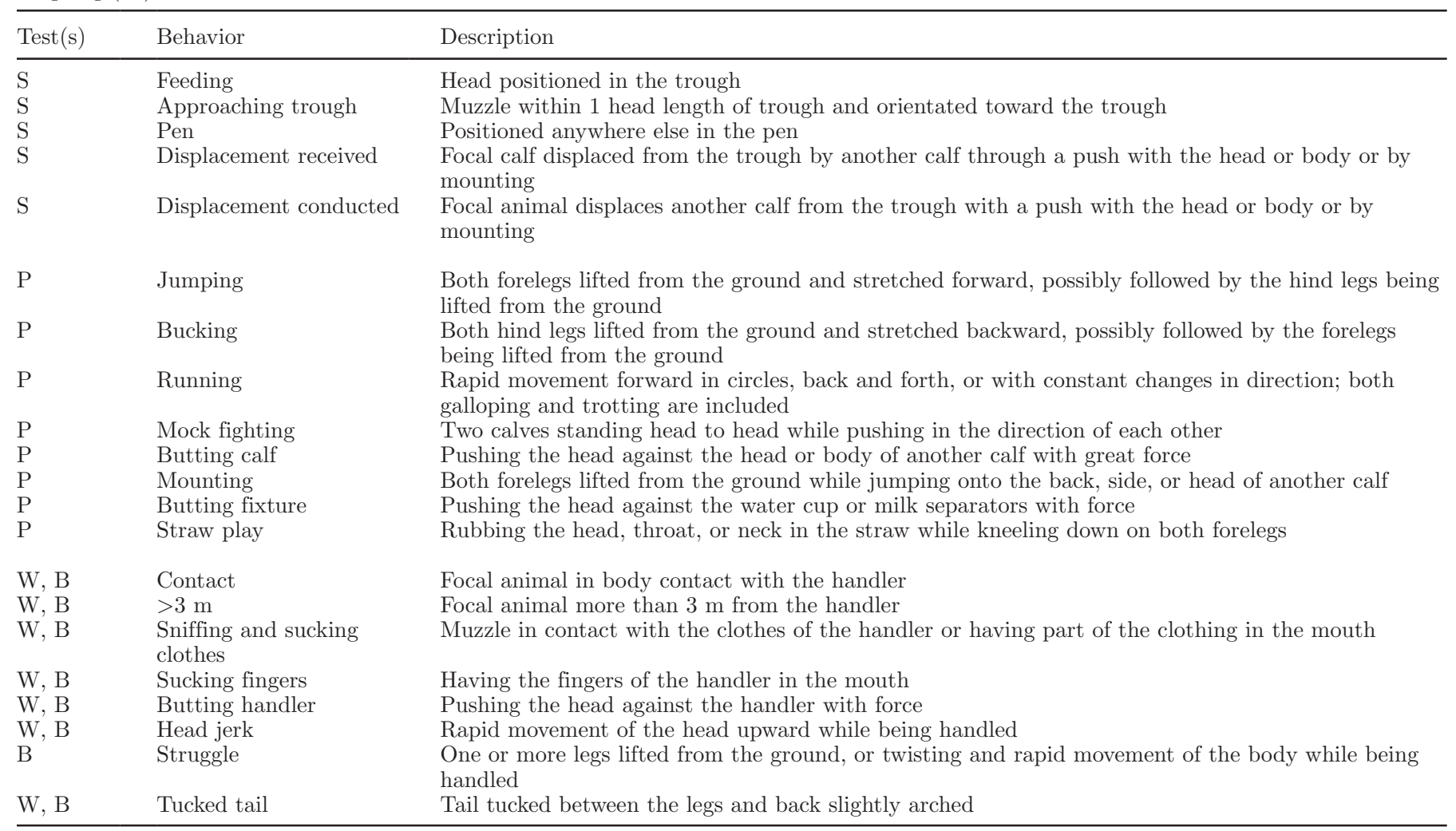

recorded. All observations in relation to the handling tests were conducted continuously on a handheld computer (Workabout, PSION PLC, London, UK), and observations were conducted only for the test calves.

Blood Sampling. The blood-sampling sessions began at $0800 \mathrm{~h}$, after calves had been fed. After assessing the response of a calf to a human, the calf was calmly caught and led to the corner of the pen opposite the entrance. The calf was kept in position by holding the head and standing beside the calf. The second handler placed a stasis chain around the lower part of the neck of the calf, at which point the observations began. Blood was taken from the large neck vein (vena jugularis). The observations ended when the calf was released. Behaviors recorded were head jerks and struggling.

Weighing. The weighing session began at $1000 \mathrm{~h}$. After assessing the response to the human, the calf was calmly caught and a halter was positioned around its head. The handler walked behind the calf, and if the calf did not walk voluntarily, it was pushed toward the entrance of the pen where the scale was positioned. The calf was placed in the scale and left there for $20 \mathrm{~s}$ while the weight was recorded. The observer recorded head jerks and tucked tail from the time the halter was placed on the calf until the calf was released back into the pen.

\section{Play Behavior}

To stimulate play behavior, fresh straw was provided in a standardized manner in the home environment on Wednesdays during wk 2 to 6 . On Sundays before this test, the pens were provided with more straw than usual, and for the next $2 \mathrm{~d}$, no fresh straw was provided in the pens. On the day of testing, loose straw ( 3 forks filled to the maximum; approximately $4.5 \mathrm{~kg}$ ) was thrown into the middle of the pen. The recording began when the straw was thrown into the first pen, and it lasted 20 min. A digital camera above each pen monitored the behavior of the calves during the test (MONACOR, Korea). For treatment $\mathrm{CH}$, a model TVCCD-460 camera was fitted with a wide-angle lens (1.6 to $3.4 \mathrm{~mm}, 1: 1.41 / 3$ in. CS). For all other treatments, a model TVCCD-140IR camera was used. Continuous video observation of the calves was used to measure the duration of jumping, bucking, running, mock fighting, butting a calf, mounting, butting a fixture, and straw play for all calves (i.e., also the companion calf in a pair). 


\section{Social Behavior}

These tests were performed to evaluate how the treatments affected the ability of the test calves to find food in a novel setting and to compete for food. When calves within a block were moved to a group pen, they were left undisturbed for $24 \mathrm{~h}$ to acclimate to the new physical and social environment. A digital camera (WV-CP230/G, Panasonic, Hamburg, Germany) with a wide-angle lens (WV-LA210C3, $2.1 \mathrm{~mm}, 1: 1.0$, Panasonic) was used to monitor the behavior of the calves during the 2 tests described below.

Alternative Feed Panel. After $24 \mathrm{~h}$ in the group pen, the calves were deprived of concentrate for $19 \mathrm{~h}$ (from 1530 to $1030 \mathrm{~h}$ the next day). Hay and water were available ad libitum. Before the test, a feed panel with 7 upright rectangular openings was put in place along the back wall of the pen. Each opening in the panel had room for the head of just 1 calf, and behind each opening was a food bowl with $1.5 \mathrm{~kg}$ of concentrate. The calves were retained in the opposite corner of the pen during the preparations and released once the panel was in place. The test began when all handlers had left the pen and the door had been closed. The test lasted $5 \mathrm{~min}$. For each test, continuous video observation of the calves was used to record calf latency to feed and the duration of the following variables: feeding, approaching the trough, position in the pen, displacements received, and displacements conducted toward other calves. After the test, the panel was removed and the calves were given access to concentrate from the trough normally used in the pen.

Feed Competition. After $48 \mathrm{~h}$ in the group pen, the calves were again deprived of access to concentrate for $19 \mathrm{~h}$ (from 1530 to $1030 \mathrm{~h}$ the next day) while hay and water were available ad libitum. Before the test, the calves were led to the corner opposite the troughs where they were usually fed. Concentrate $(21 \mathrm{~kg})$ was placed into 1 of the 4 troughs, and the calves were then released. The test began when all handlers had left the pen and the door had been closed. The test lasted 20 min. The recording method and the behaviors recorded were identical to those for the test with the alternative feed panel.

\section{Statistical Analysis}

Whenever a normal distribution could be assumed (original or after transformation), variables were analyzed with a linear mixed model. The assumption of a normal distribution was assessed by graphical checks. The basic model included milk allowance $(5$ or $9 \mathrm{~L} / \mathrm{d}$ ), social contact (individual, pair, or dam), and their interaction as fixed effects, with block included as a random effect. For data with repeated measurements on calves over the weeks, the interaction between social contact and week and the interaction between milk allowance and week were added to the basic model as fixed effects, and the unique calf number was added as a random effect to account for the repeated measurements. The random effects and the residual errors were assumed to be independently normally distributed with zero expectation and a random-effect specific variance.

If the basic model revealed an effect of the interaction, no further tests were conducted on the fixed effects included in that interaction. An interaction between social contact and milk allowance could be tested only on the $2 \times 2$ factorial part of the design (excluding the $\mathrm{CH}$ treatment). For variables in which this interaction was shown to be nonsignificant, the effect of milk allowance was tested by contrasting only calves fed the high and low allowances, which were balanced with regard to both milk allowance and social contact (again leaving out treatment $\mathrm{CH}$ ). The effect of social contact was tested by contrasting the 3 treatments with a high milk allowance ( $\mathrm{SH}, \mathrm{PH}$, and $\mathrm{CH})$, which therefore differed only in social contact. We chose this cautious procedure because the design did not allow us to test the interaction between all 3 levels of social contact and the 2 levels of milk allowance.

The analysis was conducted with the MIXED procedure of SAS (version 9.2; SAS Institute Inc., Cary, $\mathrm{NC}$ ). Results are presented as least squares means and the corresponding standard errors of the mean, $F$-value $\left(\mathrm{df}_{\text {effects }}, \mathrm{df}_{\text {error }}\right)$, and $P$-value.

For variables that could not be assumed to be normally distributed, we compared all 5 treatments with a Friedman rank test. For variables with 1 measurement per calf, the blocking in the Friedman rank test corresponded to the block in the design. For variables that were measured repeatedly over the weeks, means were calculated for each calf across the weeks and used as inputs in the analysis. When the effect of week was tested, a Friedman rank test was used, with the calf number as the blocking factor. The pairwise comparisons between treatments and weeks, respectively, were similar to Fisher's least significant difference procedure, in which the pairwise difference was considered only if the overall test was significant (Snedecor and Cochran, 1967, p. 272). The results for the Friedman rank tests are presented as medians ( 25 and $75 \%$ quantile), the test statistic $Q$, and $P$-value.

For all tests, the level of significance was set to 0.05 . Within comparisons, means without a common superscript lowercase letter differ significantly.

Handling-Blood Sampling. In the analysis, 2 observations are missing on the response to a human (treatment $\mathrm{CH}$, block 2, wk 3; treatment $\mathrm{PH}$, block 7, 
wk 6) because of technical problems. When the calves did not make contact with the handler during the test, latency to contact was set to $1.5 \mathrm{~min}$ (i.e., the duration of the test). For analysis of the reactions to restraint and blood sampling, the first $33 \mathrm{~s}$ of the observations were used for the analysis (i.e., the duration of the shortest blood-sampling session). The variables latency to contact and struggle were analyzed with a general linear mixed model for repeated measurements after transformation by the natural logarithm and square root, respectively. The remaining variables were analyzed with a nonparametric Friedman rank test.

Handling-Weighing. In the analysis, 1 observation of the response to the human is missing (treatment PL, block 8, wk 4) because of a disturbance during the test. When the calves did not make contact with the handler during the test, latency to contact was set to $1.5 \mathrm{~min}$ (i.e., the duration of the test). For the analysis on the reaction to handling, the first $28 \mathrm{~s}$ of the observations were used for the analysis (i.e., the duration of the shortest weighing session). The variables latency to contact and head jerks were analyzed with the general linear mixed model for repeated measurements (latency to contact was transformed by the natural logarithm before analysis). The variable tucked tail was converted into binary responses (animals showed a response, or no response) and tested using a generalized linear model with a binomial distribution and repeated measurements. The analysis was conducted with the PROC GLIMMIX procedure of SAS, version 9.2 (SAS Institute Inc.). The fixed effects and random effects of the model were the same as those used in the general linear mixed model. The remaining variables were analyzed with the nonparametric Friedman rank test.

Play Behavior. All play variables were pooled into a single category, called all play, because the amount of play behavior observed was limited. The mean play per pen was used in the analysis for treatments PL and PH. Week 3 was the only week when enough calves performed play behavior to fulfill the requirements for a parametric test. The basic model of the general linear mixed model was used to analyze the all play category for wk 3, and data were transformed by the natural logarithm before analysis. A Friedman rank test was used to test for an effect of week.

Social Behavior-Alternative Feed Panel. Three calves did not begin feeding during the test; thus, latency to feed was set to 5 min (i.e., the duration of the test). All variables were analyzed with the nonparametric Friedman rank test.

Social Behavior-Feed Competition. Five calves did not begin feeding within the test duration of 20 min, so their latency to begin feeding was set to 20 min for the analysis. The number of displacements received and the number of displacements conducted were square root transformed before analysis. Duration in the pen and latency to feed were transformed by the natural logarithm before analysis. The response variable feeding was analyzed with a Friedman rank test.

\section{RESULTS}

\section{Handling-Blood Sampling}

The response to a human was affected by social contact and the age of the calves. For latency to contact the handler, we found an effect of social contact (tested among calves fed a high milk allowance). Calves in the SH treatment had a shorter latency to contact the handler than did calves in the $\mathrm{PH}$ and $\mathrm{CH}$ groups $\left(F_{2,31}=\right.$ 18.5, $P<0.01$; Figure 2). Calves in the $\mathrm{SH}$ group also spent less time at a distance $>3 \mathrm{~m}$ from the handler $(Q$ $=18.0, \mathrm{df}=4, P<0.01)$ than did calves in the $\mathrm{CH}$ and $\mathrm{PH}$ groups (Table 2; comparison between all treatments). Calves in the PL group did not differ from those in the $\mathrm{PH}$ group in the time spent at a distance $>3 \mathrm{~m}$ from the handler, but the response of calves in the SL group was intermediate to those of calves in the $\mathrm{SH}$ and PL groups. Calves in the SH, SL, and PL groups spent more time in contact with the handler than did calves in the $\mathrm{CH}$ group, and the response of calves in the $\mathrm{PH}$ group was intermediate $(Q=12.9, \mathrm{df}=4, P=0.01)$. Calves in treatments SL, SH, PL, and $\mathrm{PH}$ performed more sucking clothes while in contact with the handler compared with the calves in the $\mathrm{CH}$ group, whereas the duration of butting the handler was higher for calves in the SH group compared with calves in the SL group and was minimal in the remaining treatments. No difference was found for the variable sucking fingers. With time, the duration of contact increased and the latency to contact decreased (Table 3 ).

An effect of social contact (tested among calves fed the high allowance) was detected for the handling during blood sampling. Calves in the $\mathrm{SH}$ group struggled more than calves in the $\mathrm{CH}$ group, and those in the $\mathrm{PH}$ group struggled at an intermediate level $\left(F_{2,36}=5.03\right.$, $P=0.01 ;$ Figure 2). The amount of struggling tended to vary among weeks. No treatment difference was observed in the number of head jerks $(1.5 \pm 1.5$ events $)$.

\section{Handling-Weighing}

Regarding the blood sampling sessions, an effect of social contact (tested among calves fed the high allowance) was detected for latency to contact. Calves in the SH group had a shorter latency to contact the handler 
$\left(F_{2,28}=15.9, P<0.01 ;\right.$ Figure 2$)$ than did calves in the $\mathrm{PH}$ and $\mathrm{CH}$ groups, which did not differ. Calves in the $\mathrm{SH}$ group spent more time in contact with the handler $(Q=15.7, \mathrm{df}=4, P<0.01)$ than did calves in the $\mathrm{PL}, \mathrm{PH}$, and $\mathrm{CH}$ groups, and the response of calves in the SL group was intermediate to that of calves in the SH and PL groups (Table 2; comparison between all treatments). Calves in the $\mathrm{CH}$ group spent more time at a distance $>3 \mathrm{~m}$ from the handler than did calves in all other treatments $(Q=17.7, \mathrm{df}=4, P<$ 0.01 ). No difference was found for the variables sucking fingers and sucking clothes. The duration of butting the handler was higher for calves in the SH group compared with calves in the SL group and was minimal in the remaining treatments.

During the active handling, no effect of treatment was observed for any of the variables, but the calves performed more head jerks in wk 2 and 4 compared with the number in wk 6 (wk 2: $2.8^{\mathrm{a}}$, wk $4: 2.6^{\mathrm{a}}$, wk 6 : $1.5^{\mathrm{b}}$ number of head jerks; SEM $=0.3 \mathrm{~s}, F_{2,72}=9.58, P$ $<0.001)$. No treatment difference was observed in the number of sessions in which the tucked tail posture was displayed (14 to 17 out of 24 sessions/treatment).

\section{Play Behavior}

The duration of play peaked in wk 3 and declined to low levels by wk 6 [wk $2: 5.5^{\mathrm{ab}}(0.0-31) \mathrm{s}$, wk $3: 37^{\mathrm{a}}$ $(2.5-74) \mathrm{s}$, wk $4: 14^{\mathrm{a}}(0.0-46) \mathrm{s}$, wk $5: 3.5^{\mathrm{ab}}(0.0-22) \mathrm{s}$, wk 6: $\left.0.0^{\mathrm{b}}(0.0-3.0) \mathrm{s} ; Q=18.6, \mathrm{df}=4, P<0.01\right]$. The duration of play in wk 3 (Figure 3 ) was affected by the interaction between social contact and milk allowance, with calves in the SL group spending less time playing than calves in the remaining treatments $\left(F_{1,28}=4.59\right.$, $P=0.04)$.

\section{Social Behavior-Alternative Feed Panel}

No differences were detected for any of the variables. Overall means $( \pm \mathrm{SD})$ for the response measures were latency to feed $(66 \pm 85 \mathrm{~s})$, feeding $(179 \pm 85 \mathrm{~s})$, approaching the trough $(59 \pm 68 \mathrm{~s})$, position in the pen $(32 \pm 39 \mathrm{~s})$, displacements received $(0.9 \pm 1.4$ events $)$, and displacements conducted $(0.8 \pm 1.3$ events $)$.

\section{Social Behavior_Feed Competition}

Calves in the $\mathrm{PH}$ group had a longer duration of feeding than did calves in the $\mathrm{SH}$ and $\mathrm{CH}$ groups, and calves in the remaining treatments had an intermediate duration [SL: $629^{\text {ab }}(435-952)$ s, SH: $314^{\text {bc }}(119-517)$ s, PL: $810^{\text {abc }}(483-845)$ s, PH: $771^{\text {a }}(325-833)$ s, CH: $322^{c}$ (110-384) s; $Q=11.2$, df $=4, P=0.02)$. For approaching the trough, an effect of social contact was detected a) Blood sampling
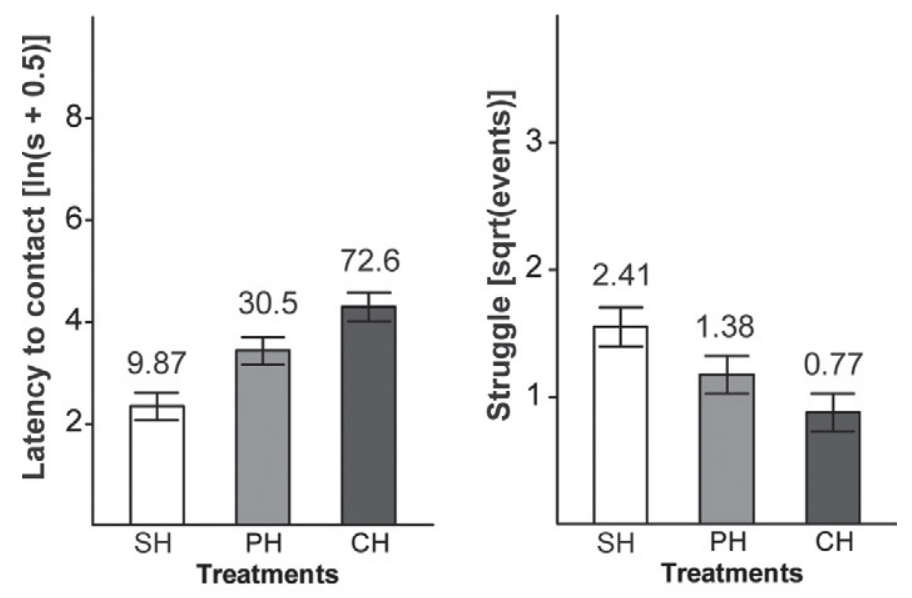

b) Weighing session

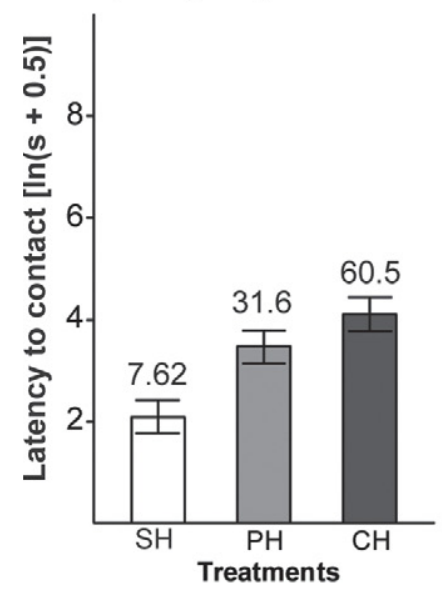

Figure 2. Effect of all 3 levels of social contact on the latency to contact and number of struggle responses during the handling tests. This effect was tested only among calves fed the high milk allowance, namely, calves housed singly on a high milk allowance (SH treatment), calves housed in pairs on a high milk allowance (PH treatment), and calves housed with the dam on a high milk allowance ( $\mathrm{CH}$ treatment). Results in relation to a) blood-sampling and b) weighing sessions are presented as least squares means \pm standard errors of the mean. Data were transformed before analysis, and the back-transformed mean is presented above each bar. Because the interaction between the 2 levels of social contact (singly and in pairs) and milk allowance [low and high ( 5 and $9 \mathrm{~L}$ of milk/d)] was nonsignificant, the effect of milk allowance is about the same for singly housed calves (treatments SL and SH) and pair-housed calves (treatments PL and PH). Results for calves housed singly on a low milk allowance (SL) and calves housed in pairs on a low milk allowance (PL) are given below for comparison. Results are given as least squares means \pm SEM and back-transformed means (in parentheses): latency to contact during blood sampling: SL 2.57 (12.6 s) and PL $3.38(28.9 \mathrm{~s})$, SEM $=0.28$; struggle during blood sampling: SL 1.51 (2.29 events) and PL 1.18 (1.39 events), SEM = 0.15; and latency to contact during a weighing session: SL 2.46 (11.2 s) and PL $3.08(21.3 \mathrm{~s}), \mathrm{SEM}=0.33$.

(tested among calves fed the high allowance). Calves in the $\mathrm{PH}$ group, with previous experience interacting with other calves, were more successful at accessing the 
O Table 2. Behavioral response toward the human handler in relation to the blood-sampling and weighing sessions for singly housed calves on a low milk allowance (SL), singly housed calves on a high milk allowance $(\mathrm{SH})$, pair-housed calves on a low milk allowance (PL), pair-housed calves on a high milk allowance $(\mathrm{PH})$, and calves housed with the cow $(\mathrm{CH})^{1}$

Treatment

\begin{tabular}{|c|c|c|c|c|c|c|c|c|}
\hline Variable & SL & $\mathrm{SH}$ & PL & $\mathrm{PH}$ & $\mathrm{CH}$ & df & $Q$-value & $P$-value \\
\hline \multicolumn{9}{|l|}{ Blood sampling } \\
\hline Contact (s) & $58^{\mathrm{a}}(33-76)$ & $50^{\mathrm{a}}(43-66)$ & $26^{\mathrm{a}}(10-59)$ & $18^{\mathrm{ab}}(10-55)$ & $0.00^{\mathrm{b}}(0.0-0.3)$ & 4 & 12.9 & 0.01 \\
\hline$>3 \mathrm{~m}(\mathrm{~s})$ & $8.8^{\mathrm{bc}}(0.0-22)$ & $0.0^{c}(0.0-6.8)$ & $31^{\mathrm{b}}(1.2-59)$ & $37^{\mathrm{b}}(3.3-53)$ & $58^{\mathrm{a}}(42-70)$ & 4 & 18.0 & $<0.01$ \\
\hline Sucking finger (s) & $23(5.9-61)$ & $12(1.8-36)$ & $18(6.6-36)$ & $6.1(0.3-15)$ & $0.00(0.0-0.3)$ & 4 & 8.41 & 0.08 \\
\hline Sucking clothes (s) & $22^{\mathrm{a}}(2.1-27)$ & $20^{\mathrm{a}}(9.7-36)$ & $2.7^{\mathrm{a}}(0.5-17)$ & $9.7^{\mathrm{a}}(2.3-30)$ & $0.000^{\mathrm{b}}(0.00-0.00)$ & 4 & 14.9 & $<0.01$ \\
\hline Butting handler (s) & $1.2^{\mathrm{b}}(0.0-1.8)$ & $5.8^{\mathrm{a}}(2.4-13)$ & $0.00^{\mathrm{c}}(0.0-0.4)$ & $0.000^{\mathrm{bc}}(0.00-0.00)$ & $0.000^{\mathrm{c}}(0.00-0.00)$ & 4 & 18.3 & $<0.01$ \\
\hline \multicolumn{9}{|l|}{ Weighing sessions } \\
\hline Contact (s) & $56^{\mathrm{ab}}(31-77)$ & $55^{\mathrm{a}}(38-76)$ & $21^{\mathrm{b}}(14-55)$ & $34^{\mathrm{bc}}(1.8-50)$ & $0.3^{\mathrm{c}}(0.0-14)$ & 4 & 15.7 & $<0.01$ \\
\hline$>3 \mathrm{~m} \mathrm{(s)}$ & $3.5^{\mathrm{b}}(0.0-15)$ & $0.0^{\mathrm{b}}(0.0-8.3)$ & $11^{\mathrm{b}}(0.0-42)$ & $5.0^{\mathrm{b}}(0.0-36)$ & $59^{\mathrm{a}}(57-72)$ & 4 & 17.7 & $<0.01$ \\
\hline Sucking finger (s) & $37(8.2-52)$ & $38(21-65)$ & $9.8(0.0-40)$ & $7.0(0.0-24)$ & $0.0(0.0-3.3)$ & 4 & 8.65 & 0.07 \\
\hline Sucking clothes (s) & $24(0.0-34)$ & $12(4.7-16)$ & $7.7(4.3-18)$ & $5.0(0.0-25)$ & $0.0(0.0-4.5)$ & 4 & 5.02 & 0.29 \\
\hline Butting handler (s) & $1.3^{\mathrm{ab}}(0.0-3.0)$ & $2.5^{\mathrm{a}}(0.0-7.7)$ & $0.000^{\mathrm{c}}(0.00-0.00)$ & $0.000^{\mathrm{abc}}(0.00-0.00)$ & $0.000^{\mathrm{bc}}(0.00-0.00)$ & 4 & 11.1 & 0.03 \\
\hline
\end{tabular}

${ }^{\mathrm{a}-\mathrm{c}}$ Medians within a row with different superscripts differ $(P<0.05)$

${ }^{1}$ All 5 treatments were compared with a Friedman rank test. Results are presented as the median (25 to $75 \%$ quantiles are shown in parentheses).

Table 3. Behavioral responses toward the human handler in relation to blood-sampling (wk 1 to 6 ) and weighing sessions (wk 2, 4, and 6 )

\begin{tabular}{|c|c|c|c|c|c|c|c|c|c|}
\hline Variable & wk 1 & wk 2 & wk 3 & wk 4 & wk 5 & wk 6 & df & $F / Q$ & $P$-value \\
\hline \multicolumn{10}{|l|}{ Blood sampling } \\
\hline Contact $^{1}(\mathrm{~s})$ & $1.5^{\mathrm{c}}(0.0-50)$ & $12^{\mathrm{bc}}(0.0-68)$ & $43^{\mathrm{ab}}(0.0-83)$ & $15^{\mathrm{b}}(0.0-72)$ & $26^{\mathrm{bc}}(0.0-71)$ & $63^{\mathrm{a}}(0.0-81)$ & 5 & 31.3 & $<0.01$ \\
\hline $\begin{array}{l}\text { Latency to } \\
\text { contact }^{2,3}(\mathrm{~s})\end{array}$ & $3.7^{\mathrm{a}} \pm 0.2(41.3)$ & $3.4^{\mathrm{b}} \pm 0.2(28.6)$ & $3.0^{\mathrm{cd}} \pm 0.2(19.9)$ & $3.2^{\mathrm{bc}} \pm 0.2(23.2)$ & $3.1^{\mathrm{bc}} \pm 0.2(22.7)$ & $2.8^{\mathrm{d}} \pm 0.2(15.9)$ & 5,134 & 15.6 & $<0.01$ \\
\hline Struggle $^{2,4}$ (events) & $1.5 \pm 0.1(2.4)$ & $1.1 \pm 0.1(1.2)$ & $1.3 \pm 0.1(1.7)$ & $1.0 \pm 0.1(1.1)$ & $1.3 \pm 0.1(1.7)$ & $1.3 \pm 0.1(1.6)$ & 5,181 & 2.20 & 0.06 \\
\hline \multicolumn{10}{|l|}{ Weighing sessions } \\
\hline Contact $^{1}(\mathrm{~s})$ & & $17(0.0-61)$ & & $46(0.0-74)$ & & $39(0.0-83)$ & 2 & 4.05 & 0.13 \\
\hline $\begin{array}{l}\text { Latency to } \\
\text { contact }^{2,3}(\mathrm{~s})\end{array}$ & & $3.4^{\mathrm{a}} \pm 0.3(28.6)$ & & $3.0^{\mathrm{b}} \pm 0.3(20.5)$ & & $2.7^{\mathrm{c}} \pm 0.3(14.6)$ & 2,71 & 10.1 & $<0.01$ \\
\hline
\end{tabular}

${ }^{\mathrm{a}-\mathrm{d}}$ Medians or least squares means within a row with different superscripts differ $(P<0.05)$.

${ }^{1}$ Weeks were compared with a Friedman rank test. Results are presented as the median (25 to $75 \%$ quantiles are shown in parentheses).

${ }^{2}$ Weeks were compared with a linear mixed model. Results are presented as least squares means \pm standard errors of the mean.

${ }^{3}$ Estimates of natural logarithmically transformed data. The back-transformed mean is presented in parentheses.

${ }^{4}$ Estimates of square root-transformed data. The back-transformed mean is presented in parentheses. 


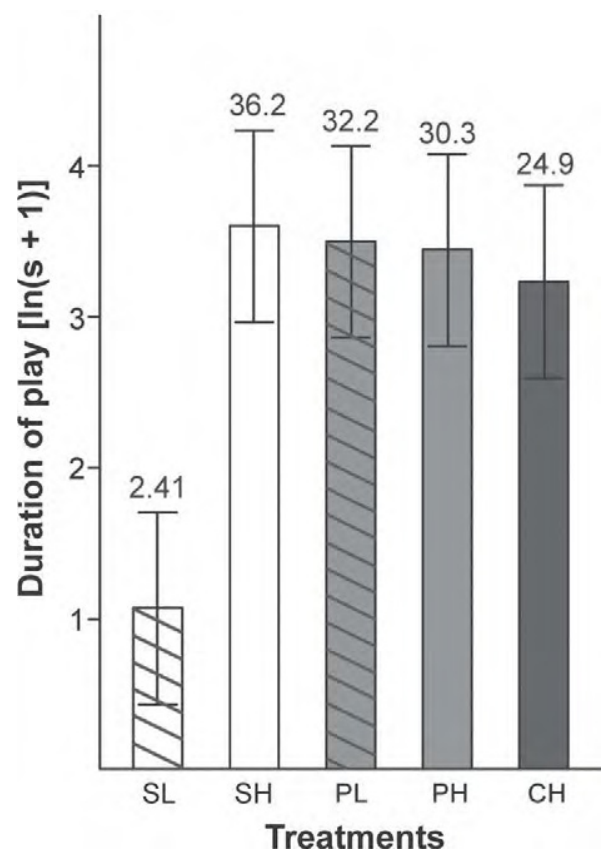

Figure 3. The duration of all play in wk 3. Calves housed singly on a low $(5 \mathrm{~L}$ of milk/d) milk allowance (SL), calves housed singly on a high (9 L of milk/d) milk allowance $(\mathrm{SH})$, calves housed in pairs on a low milk allowance (PL), calves housed in pairs on a high milk allowance $(\mathrm{PH})$, and calves housed with the dam on a high milk allowance $(\mathrm{CH})$. Analyzed with a general linear mixed model; results are presented as least squares means \pm standard errors of the mean. Data were natural logarithmically transformed before analysis, and the back-transformed mean is presented above each bar.

trough than were calves in the $\mathrm{SH}$ and $\mathrm{CH}$ groups [approaching the trough for $\mathrm{SH}: 146^{\mathrm{ab}}, \mathrm{PH}: 84.88^{\mathrm{b}}, \mathrm{CH}$ : $194^{\mathrm{a}} \mathrm{s} ; \mathrm{SEM}=31 \mathrm{~s}, F_{2,28}=3.83, P=0.03$ (for comparison, SL: 157 s, PL: 75,88 s; SEM $=31$ s)]. Calves on a high milk allowance (tested among singly housed and pair-housed calves) spent more time in the pen [i.e., away from the trough; low milk allowance: $5.3^{\mathrm{b}}(192$ $\mathrm{s})$, high milk allowance: $6.1^{\mathrm{a}}(424 \mathrm{~s}) ; \mathrm{SEM}=0.2, F_{2,35}$ $=5.10, P=0.03]$ and tended to have a longer latency to their first feeding bout (low milk allowance: $2.6^{\mathrm{b}}(13$ $\mathrm{s})$, high milk allowance: $4.0^{\mathrm{a}}(54 \mathrm{~s}) ; \mathrm{SEM}=0.5, F_{2,28}=$ $3.41, P=0.08)$. For the remaining response variables, no effect of treatment was observed.

\section{DISCUSSION}

\section{Handling}

The effect of social contact on the response of the calves to the presence of a passive handler in the pen was similar to that observed in previous studies (Lensink et al., 2001; Krohn et al., 2003). The singly housed calves had a shorter latency to contact the han- dler than did pair-housed and dam-reared calves and had a longer duration of contact than did dam-reared calves. Not only were the dam-reared calves the least likely to approach the handler, but they also kept the greatest distance from the handler. The differences in the response to a passive human were likely due to the bond between the dam and her calf (Krohn et al., 2003; Newberry and Swanson, 2008) and the social relationship between peers (Raussi et al., 2003; Duve and Jensen, 2011). In contrast, the singly housed calves did not have the opportunity to form relationships with conspecifics, and thus likely formed a stronger relationship with their human handlers. Previous work has shown that pair-housed calves choose to spend more time with a peer if given the choice between a peer and a human, but singly housed calves show no preference between peers and humans (Raussi et al., 2003).

The calves were likely able to tell the difference between a blood-sampling session and a weighing session before the actual handling because of the difference in the equipment positioned outside the pen (i.e., a table with test tubes vs. a scale). Calves may have considered the blood-sampling sessions more aversive than the weighing sessions, and this might possibly explain why the calves kept a greater distance and engaged in fewer sucking finger events during the blood-sampling sessions compared with the weighing sessions.

Krohn et al. (2003) suggested that calves housed with the dam are more fearful of humans than are singly housed calves, based on their approach to humans and flight distance. To provide a more explicit test of fearfulness during handling, we measured calf responses during a period of restraint. Although the pair-housed and dam-reared calves interacted less with the passive human, they did not appear to find restraint more stressful. Indeed, the results of the current study showed that the singly housed calves struggled more during restraint than did the dam-reared calves and that the pair-housed calves struggled at intermediate levels. Restraint is considered stressful in other species, including deer (Carragher et al., 1997; Chaya et al., 2006) alpacas (Pollard and Littlejohn, 1995), and quail (Jones et al., 2000). The struggle response has been particularly well studied in laboratory rats, and for this species, struggling is considered a quantifiable stressinduced behavior (Grissom et al., 2008). We suggest that even though the singly housed calves had a higher motivation for contact with the handler, they found restraint more stressful. This interpretation is consistent with results from Raussi et al. (2003), who found that singly housed calves were more responsive to an $\mathrm{ACTH}$ challenge, and thus seemed to have a higher chronic stress level than did pair-housed calves. 


\section{Play Behavior}

We found an interaction between social contact and milk allowance on the duration of play behavior performed; calves housed under standard conditions (SL treatment) played less than did the calves in all other treatments. Play behavior may be related to animal welfare in 2 ways. First, juveniles are motivated to play when their primary needs are met, and second, play behavior is reinforcing and associated with positive emotions (Jensen et al., 1998; Yeates and Main, 2008; Krachun et al., 2010; Held and Špinka, 2011).

Jensen et al. (1998) found a peak in play behavior after provision of straw; therefore, we decided to concentrate our observations around the time when fresh bedding was added to the pen. The duration of play behavior observed in this study was low, but play is known to occur sporadically over the course of the day. We therefore recommend longer periods of observation for play behavior in future studies.

Among singly housed calves, a high milk allowance increased play behavior in this study. Similarly, Krachun et al. (2010) found more spontaneous locomotor play in dairy calves fed a high versus a low milk allowance. Krachun et al. (2010) and the current study also showed that play was reduced when the milk allowance was reduced at weaning.

Babu et al. (2004) found more play behavior in grouphoused calves than in singly housed calves. However, social contact and space allowance were confounded in their study, and space allowance alone is known to affect the level of play behavior (Jensen et al., 1998; Jensen and Kyhn, 2000). In the current study, these 2 factors were not confounded, and the lower level of play for calves in the SL group suggests that the combination of a low milk allowance and single housing suppresses this behavior.

\section{Social Behavior}

We expected the singly housed calves to have a longer latency to begin feeding in the test with the alternative feed panel because of potentially poorer cognitive performance in singly housed calves (De Paula Vieira et al., 2010). However, no significant differences between treatments were found. In the current study, the latency to feed was low for all treatments, suggesting that the task was easy for the calves. At this point, however, it is not possible to determine whether the similar response of the different social levels in this test was due to the design of the test or to similar cognitive abilities of singly and pair-housed calves.
In the feed competition test, calves in the $\mathrm{PH}$ group spent more time feeding and less time trying to access the trough than did calves in the SH group, which suggests that social housing improves competitive success. The tendency for a shorter latency to feed for calves on a low milk allowance compared with calves on a high milk allowance, and the fact that calves on a high milk allowance spent more time away from the trough suggest that the low milk allowance increased the motivation to access concentrate. Nielsen (1999) suggested that periods of feed restriction can have longterm consequences for the rate of eating in rats and pigs, which is a good indicator of feeding motivation. Calves on a low milk allowance experience feed restriction, especially during the first $2 \mathrm{wk}$ of life, when they consume little solid feed (Khan et al., 2011). Thereafter, limit-fed calves consume more concentrate than do calves provided more milk, and this greater familiarity with concentrate preweaning may have increased the motivation to consume starter feed during this test.

We did not consider the calves in the $\mathrm{CH}$ group in the feed competition test because these calves consumed very little concentrate before weaning. Forage intake was not recorded, but we observed that calves in the $\mathrm{CH}$ group frequently consumed feed from the feeder of the dam.

\section{CONCLUSIONS}

Social contact with the dam reduced the struggle response of the calves in response to restraint, and social contact with a peer increased the competitive success of the calves. The effects of contact with a peer were in the same direction as the effects of contact with the dam, and we suggest that social contact affects calf welfare positively. The level of play behavior stimulated by provision of straw was low, but calves housed singly and fed a low milk allowance performed less play than did calves in the remaining treatments, indicating a lower motivation to play in these calves. Postweaning, calves that had been fed a high milk allowance were less motivated to approach the concentrate than were calves that had been fed a low milk allowance.

\section{ACKNOWLEDGMENTS}

Thanks to Charlotte Gaillard (Agrocampus Quest, Rennes, France), John M. Obidah, Tanja H. Andersen, Louise Christensen, and Erik L. Decker (all of Faculty of Science and Technology, Department of Animal Science, Tjele, Denmark) for assisting with data collection. 


\section{REFERENCES}

Babu, L. K., H. N. Pandey, and A. Sahoo. 2004. Effect of individual versus group rearing on ethological and physiological responses of crossbred calves. Appl. Anim. Behav. Sci. 87:177-191.

Boissy, A., G. Manteuffel, M. B. Jensen, R. O. Moe, B. Spruijt, L. J. Keeling, C. Winckler, B. Forkman, I. Dimitrov, J. Langbein, M. Bakken, I. Veissier, and A. Aubert. 2007. Assessment of positive emotions in animals to improve their welfare. Physiol. Behav. 92:375-397.

Bouissou, M.-F., A. Boissy, P. Le Neindre, and I. Veissier. 2001. The social behaviour of cattle. Pages 113-145 in Social Behavior in Farm Animals. L. J. Keeling and H. Gonyou, ed. CABI Publishing, Cambridge, MA.

Carragher, J. F., J. R. Ingram, and L. R. Matthews. 1997. Effects of yarding and handling procedures on stress responses of red deer stags (Cervus elaphus). Appl. Anim. Behav. Sci. 51:143-158.

Chaya, W., J. Pollard, and R. Littlejohn. 2006. A note on stability of behavioural reactions to handling in red deer hinds and their calves. Appl. Anim. Behav. Sci. 101:177-182.

de Passillé, A. M., and J. Rushen. 2006. Calves' behaviour during nursing is affected by feeding motivation and milk availability. Appl. Anim. Behav. Sci. 101:264-275.

De Paula Vieira, A., M. A. G. von Keyserlingk, and D. M. Weary. 2010. Effects of pair versus single housing on performance and behavior of dairy calves before and after weaning from milk. J. Dairy Sci. 93:3079-3085.

Duve, L. R., and M. B. Jensen. 2011. The level of social contact affects social behaviour in pre-weaned dairy calves. Appl. Anim. Behav. Sci. 135:34-43.

Færevik, G., M. B. Jensen, and K. E. Bøe. 2006. Dairy calves social preference and the significance of a companion animal during separation from the group. Appl. Anim. Behav. Sci. 99:205-221.

Grignard, L., A. Boissy, X. Boivin, J. P. Garel, and P. Le Neindre. 2000. The social environment influences the behavioural responses of beef cattle to handling. Appl. Anim. Behav. Sci. 68:1-11.

Grissom, N., W. Kerr, and S. Bhatnagar. 2008. Struggling behavior during restraint is regulated by stress experience. Behav. Brain Res. 191:219-226.

Held, S. D. E., and M. Špinka. 2011. Animal play and animal welfare. Anim. Behav. 81:891-899.

Holm, L., M. B. Jensen, and L. L. Jeppesen. 2002. Calves' motivation for access to two different types of social contact measured by operant conditioning. Appl. Anim. Behav. Sci. 79:175-194.

Jasper, J., and D. M. Weary. 2002. Effects of ad libitum milk intake on dairy calves. J. Dairy Sci. 85:3054-3058.

Jensen, M. B., and R. Kyhn. 2000. Play behaviour in group-housed dairy calves, the effect of space allowance. Appl. Anim. Behav. Sci. $67: 35-46$.

Jensen, M. B., L. Munksgaard, L. Mogensen, and C. C. Krohn. 1999. Effects of housing in different social environments on open-field and social responses of female dairy calves. Agric. Scand. A Anim. Sci. Anim. Sci. 49:113-120.

Jensen, M. B., K. S. Vestergaard, and C. C. Krohn. 1998. Play behaviour in dairy calves kept in pens: The effect of social contact and space allowance. Appl. Anim. Behav. Sci. 56:97-108.

Jensen, M. B., K. S. Vestergaard, C. C. Krohn, and L. Munksgaard. 1997. Effect of single versus group housing and space allowance on responses of calves during open-field tests. Appl. Anim. Behav. Sci. 54:109-121.
Jones, R. B., D. G. Satterlee, D. Waddington, and G. G. Cadd. 2000. Effects of repeated restraint in Japanese quail genetically selected for contrasting adrenocortical responses. Physiol. Behav. 69:317324.

Khan, M. A., H. J. Lee, W. S. Lee, H. S. Kim, S. B. Kim, K. S. Ki, J. K. Ha, H. G. Lee, and Y. J. Choi. 2007. Pre- and postweaning performance of Holstein female calves fed milk through step-down and conventional methods. J. Dairy Sci. 90:876-885.

Khan, M. A., D. M. Weary, and M. A. G. von Keyserlingk. 2011. Invited review: Effects of milk ration on solid feed intake, weaning and performance in dairy heifers. J. Dairy Sci. 94:1071-1081.

Krachun, C., J. Rushen, and A. M. de Passille. 2010. Play behaviour in dairy calves is reduced by weaning and by a low energy intake. Appl. Anim. Behav. Sci. 122:71-76.

Krohn, C. C. 2001. Effects of different suckling systems on milk production, udder health, reproduction, calf growth and some behavioural aspects in high producing dairy cows-A review. Appl. Anim. Behav. Sci. 72:271-280.

Krohn, C. C., X. Boivin, and J. G. Jago. 2003. The presence of the dam during handling prevents the socialization of young calves to humans. Appl. Anim. Behav. Sci. 80:263-275.

Lensink, B. J., S. Raussi, X. Boivin, M. Pyykkönen, and I. Veissier. 2001. Reactions of calves to handling depend on housing condition and previous experience with humans. Appl. Anim. Behav. Sci. 70:187-199.

Newberry, R. C., and J. C. Swanson. 2008. Implications of breaking mother-young social bonds. Appl. Anim. Behav. Sci. 110:3-23.

Nielsen, B. L. 1999. On the interpretation of feeding behaviour measures and the use of feeding rate as an indicator of social constraint. Appl. Anim. Behav. Sci. 63:79-91.

Pollard, J. C., and R. P. Littlejohn. 1995. Effects of social-isolation and restraint on heart-rate and behavior of alpacas. Appl. Anim. Behav. Sci. 45:165-174.

Raussi, S., B. J. Lensink, A. Boissy, M. Pyykkönen, and I. Veissier. 2003. The effect of contact with conspecifics and humans on calves' behaviour and stress responses. Anim. Welf. 12:191-203.

Snedecor, G. W., and W. G. Cochran. 1967. Statistical Methods. 6th ed. The Iowa State University Press, Ames.

Špinka, M., R. C. Newberry, and M. Bekoff. 2001. Mammalian play: Training for the unexpected. Q. Rev. Biol. 76:141-168.

Sweeney, B. C., J. Rushen, D. M. Weary, and A. M. de Passillé. 2010. Duration of weaning, starter intake, and weight gain of dairy calves fed large amounts of milk. J. Dairy Sci. 93:148-152.

Takeda, K., S. Sato, and K. Sugawara. 2003. Familiarity and group size affect emotional stress in Japanese Black heifers. Appl. Anim. Behav. Sci. 82:1-11.

Veissier, I., V. Gesmier, P. Le Neindre, J. Y. Gautier, and G. Bertrand. 1994. The effects of rearing in individual crates on subsequent social behaviour of veal calves. Appl. Anim. Behav. Sci. 41:199-210.

Vitale, A. F., M. Tenucci, M. Papini, and S. Lovari. 1986. Social behaviour of the calves of semi-wild Maremma cattle, Bos primigenius taurus. Appl. Anim. Behav. Sci. 16:217-231.

von Keyserlingk, M. A. G., and D. M. Weary. 2007. Maternal behavior in cattle. Horm. Behav. 52:106-113.

Wood-Gush, D. G. M., K. Hunt, K. Carson, and S. G. C. Dennison. 1984. The early behaviour of suckler calves in the field. Biol. Behav. 9:295-306.

Yeates, J. W., and D. C. J. Main. 2008. Assessment of positive welfare: A review. Vet. J. 175:293-300. 